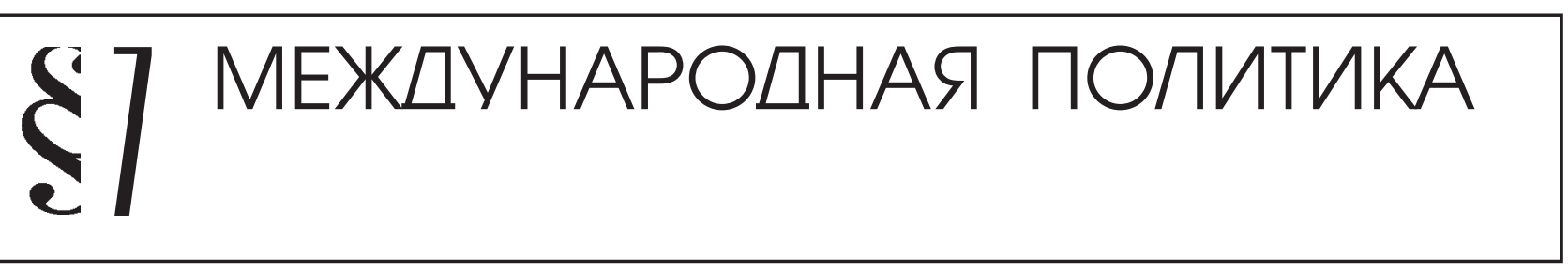

\title{
А.Ю. Бельянинов
}

\section{ПОЛИТИЧЕСКАЯ И СОЦИАЛЬНО-ЭКОНОМИЧЕСКАЯ РОЛЬ РОССИИ В ИНТЕГРАЦИОННОМ ПРОЦЕССЕ НА ПОСТСОВЕТСКОМ ПРОСТРАНСТВЕ}

\begin{abstract}
Аннотация: В настоящей статьеанализируетсягеополитические и социально-экономические аспекты внешней политики России на примере Евразийского экономического союза, дается характеристика тенденциям в мировом сообществе, происходящим под влиянием формирования нового мирового порядка.Утверждается, что новый толчок к смене глобальной парадигмы развития был дан началом мирового экономического кризиса в 20072008 годы. Кризис поматнул утопическую веру победивщего в «холодной войне» либерализма в бескризисное, в широком смысле, развитие в глобальном постиндустриальном мире.
\end{abstract}

Ключевые слова: Россия, интеграция, постсоветское пространство, политика, экономика, безопасность, международные отномения, глобализачия, регионализация, федерализм, конфликт, национальные интересы.

$\mathrm{O}$ кончание второй мировой войны и распад колониальной системы во второй половине $\mathrm{XX}$ в. дали импульс политической и экономической глобализации. Этот сдвиг сопровождался беспрецедентным в мировой истории ростом добычи и использования природных ресурсов, конкуренции за эти и иные - демографические, научные и технологические ресурсы.

Глобализация была в целом основана на двух конкурирующих политических идеологиях. С одной стороны, либерализма, который стал основой развития Запада, прежде всего США и стран Западной Европы ${ }^{1}$. С другой стороны - социализма, который стал основой развития Востока, прежде всего СССР и стран восточной Европы. Именно эти идеологии и породили биполярную мировую систему, сохранявшую устойчивый баланс сил в мире.

Однако глобализация постепенно исчерпала себя, перешла определенную знаковую черту к началу последней четверти XX века. Этот переход был связан с беспрецедентным ростом научно-технических, главным образом военно-технических возможностей, с освоением космоса, развитием электронных

${ }^{1}$ Современная политическая теория / Авт.-сост. Д. Хэлд. M., 2001. технологий и биотехнологий, генной инженерии и ряда других прорывных технологий. С этого исторического момента изменения всего мирового порядка стали необратимыми.

Эти изменения стали одной из ключевых причин краха не только социализма советского образца, но и распада СССР и восточного блока. Фиаско потерпел и сам либерализм, который утратил своего конкурента и исчерпал тем самым свою историческую миссию. Мир стал более консервативным и перешел в стадию однополярного развития.

Тем не менее, в современном мире продолжается формирование мирового пространства, первоначально начатое противостоянием двух экономических и геополитических субъектов мировой истории - Западного мира (США и ЕС) и Восточного мира (СССР - Россией). Причем, движущая сила и основная цель этого противостояния - достижение единоличного лидерства в мире, мировой политике и мировой экономике, то есть формирование однополярного мирового порядка. И такой порядок продолжают выстраивать в настоящее время США, хотя это и активно оспаривается Китаем.

Серьезным результатом такого противостояния явился распад ведущего центра Восточного мира СССР, что стало, как выразился В.В.Путин, «гло- 


\section{Политика и общество $5(101) \cdot 2013$}

бальной геополитической катастрофой». Этот распад привел к демонтажу сложившейся к тому времени биполярной системы мирового пространства ${ }^{2}$, сгенерировал крупные, продолжающиеся до сих пор экономические, демографические и геополитические сдвиги во многих регионах мира.

К таким регионам мира относятся, главным образом, Восточная и Юго-Восточная Европа, Кавказ и Ближний Восток, Средняя и Центральная Азия. Фактически - это огромная часть евразийского континента, которая исторически и объективно находилась длительное время в зоне влияния России, как интеграционного и объединяющего ядра.

Распад СССР, как и ранее распад Российской империи, создал очередной геополитический вакуум на огромных территориях Евразии ${ }^{3}$ Проблема состоит в том, что современные тенденции мирового развития ведут не к ликвидации, а к разрастанию этого вакуума, который приобретает, по некоторым оценкам, катастрофический характер. Тем более, в условиях усиления конкуренции за богатые энергетические и иные сырьевые ресурсы, которые находятся как в России, так и в ряде других постсоветских стран.

Заполнение бесконтрольного, фактически и непрерывно расширяющегося геополитического и социально-экономического вакуума на постсоветском пространстве ${ }^{4}$, а также защита указанных ресурсов являются одними из ключевых целей и задач будущего Евразийского экономического союза. Формирование этого союза и определение путей его дальнейшего движения прежде зависит прежде всего от позиции, политики и решений ядра ЕАЭС, то есть России.

В сложившихся условиях Россия должна активно включаться в процесс создания нового мирового порядка. Однако активность и равноправность такого включения должны иметь концептуальные основания. Иначе говоря, это включение должно происходить на основе внешнеполитической доктрины, дающей ключ к решению актуальных мировых и региональных проблем. Такая доктрина - это по сути концепция ЕАЭС и многополярного мира.

\footnotetext{
${ }^{2}$ Бусыгина И.М. Модернизация и проблема эффективности государства // Политическая модернизация России в экспертном сознании. М.: Изд-во «Проспект», 2011. С. 86-97.

${ }^{3}$ Гаджиев К.С. Геополитика. М.: Международные отношения, 1997.

${ }^{4}$ Алексеев Р.А. Общетеоретические начала федерализма: понятие и признаки // Вопросы политологии. 2012. №1.
}

Принятие Россией функций интеграционного ядра или основы ЕАЭС означает, что Россия должна принять на себя также целый ряд односторонних обязательств, связанных с созданием механизмов реализации этих функций. Такое требование не является чем-то исключительным в мировой истории и должно быть признано всеми потенциальными участниками ЕАЭС изначально.

В действительности, такие обязательства и механизмы имеют в мировой истории универсальный характер, именно они позволяли различным странам в прошлом добиваться статуса мировых или региональных держав, т.е. мировых или региональных центров. Более того, именно такие обязательства и механизмы позволяли им сохранять этот статус достаточно длительное время и на больших территориях, в том числе удаленных от метрополий.

Подобный статус имели в мировой истории крупные империи и «импероподобные» государства, как союзы более или менее развитых стран, создаваемые в той или иной политической и геополитической конфигурации.

Распад Российской империи привел, в конечном счете, к распаду Британской империи, к усилению США и началу их доминирования в мире и в мировой экономике. Распад СССР также придал сильный толчок изменениям в мировой экономике за последние двадцать лет и, очевидно, расчистил место для создания пока однополярного мира во главе США.

Более того, именно распад СССР привел также и к усилению Евросоюза, вызвав исключительно политическое решение об ускорении расширения этого союза за счет стран Восточной Европы, которые не соответствовали по уровню экономического и политического развития критериям вступления в ЕС. В определенной степени именно это решение стало одной из причин современного кризиса в Евросоюзе ${ }^{5}$, как отголоска распада СССР и следствием самой значимости этого распада.

В современном мире механизм смены лидера мировой системы, распада одних стран и союзов стран и усиление других стран и союзов продолжает действовать. Хотя в реальности возможности для переходов стран из мировой периферии в мировой центр, а менее развитых стран - в более развитые, лимитированы инертностью мировых процессов. Более того, та-

\footnotetext{
${ }_{5}^{5}$ Барсуков А.М. Политический кризис бельгийского федерализма // Вопросы политологии. 2012. №1.
} 
DOI: $10.7256 / 1812-8696.2013 .05 .8$

Международная политика

кие переходы ограничены по причине разобщенности стран мировой периферии, их взаимной конкуренцией за особые экономические и политические отношения с государствами мирового центра, сегодня это - США, Евросоюз и Китай.

Разобщенность между постсоветскими странами и их соревнование за особые отношения с центральными государствами является ключевым признаком современного состояния евразийского пространства ${ }^{6}$. Преодоление такой разобщенности и состояния неконтролируемой взаимной конкурентности в экономике и политике - это главная цель и условие не только создания, но и развития ЕАЭС.

Существование определенных ограничений в действии механизма смены мировых центров и периферии имеет объективные причины. В действительности, отсутствие каких-либо сдерживающих факторов, стихийность и неуправляемость функционирования этого механизма приводило бы не к мировому порядку, а к мировому хаосу. Поэтому в мировой истории число стран-центров всегда было весьма ограниченным, тогда как большинство остальных государств составляли и продолжают составлять лишь более или менее активную часть мировой периферии.

Это связано с тем, что мировые центры не только устанавливают соответствующий их пониманию порядок в доступном им мире. Они длительное время поддерживают такой порядок, несут геополитическую, политическую, социально-экономическую и культурную ответственность ${ }^{7}$ и соответствующие издержки. Более того, от мировых центров требуются для этого большие материальные и культурные затраты, иногда и в ущерб их национальным интересам. Без этого ни одной стране не удавалось добиваться статуса мирового центра и удерживать его длительное время.

В мировой истории всегда существует многополярный мироуклад, значительно реже ситуация однополярного мира, в котором мировой порядок формируется одним полюсом - мировым центром. Именно на такие центры ориентировались и продолжают ориентироваться, в конечном счете, все остальные страны периферии. В том числе и через формируемые ими, в

\footnotetext{
6 Жидких В.А. Российский федерализм: эволюция, проблемы и перспективы развития. М.: Современная экономика и право, 2009.

${ }^{7}$ Тишков В. А. Этнология и политика. Научная публицистика. М., 2001.
}

целях такой ориентации, крупные региональные центры или союзы.

Попытки изменения мирового порядка с целью создания многополярного мира будут сталкиваться с мировыми международными организациями, преследующими основную для них задачу на сегодня - сохранить сложившееся соотношение сил в мире. Прежде всего - в национальных и транснациональных интересах сложившегося мирового центра. В настоящее время - в интересах США, которые и создавали такие организации и продолжают сохранять над ними контроль.

Главный аргумент в пользу такой охранительной деятельности этих организаций состоит в необходимости предотвратить разрушение сложившегося мирового порядка и стран, носителей такого порядка. Согласно этому, такое разрушение будет иметь масштабные негативные геополитические и социально-экономические последствия для многих странкак мирового центра, так и периферии, в том числе для России и других постсоветских стран.

На самом же деле, многие действия именно крупнейших мировых экономических и политических центров Запада, прежде всего США, снижают, и иногда существенно, устойчивость мирового порядка и мировой экономики, во все возрастающей мере порождают новые глобальные и региональные проблемы и риски, увеличивают социальное и этнокультурное напряжение в мире и во многих его регионах. В силу этого такие внешние вызовы заставляют Россию и другие постсоветские страны принимать свои суверенные решения в области экономики, политики и интеграции.

Именно поэтому так важно повышение влияния России в международных организациях. Тем более, что среди постсоветских стран именно Россия входит в состав сложившегося мирового центра - в формате G20 и G8 - с ее наиболее естественной зоной ответственности - Евразией.

Одними из ключевых вопросов интеграции на постсоветском пространстве является состояние и перспективы отношений России и постсоветских стран с Европейским Союзом, а также вопросы приоритетов евразийской и европейской векторов экономической интеграции. В решении этих вопросов существуют два основных подхода.

Так, согласно первому подходу, участие в Таможенном союзе (ТС) и ЕЭП не позволит ряду постсоветских стран реализовать принятый ими курс на интеграцию с Евросоюзом, якобы поэтому эти страны не 


\section{Политика и общество $5(101) \cdot 2013$}

участвуют в интеграционных проектах в сфере экономики. Между тем, одна из задач ЕАЭС и состоит как раз в том, чтобы позволить его участникам быстрее, но на более сильных коллективных позициях интегрироваться в Европу.

Напротив, сторонники другого подхода отрицают возможность создания общеевропейского экономического пространства от Ванкувера до Владивостока и не считают евроатлантические страны партнерами России и других постсоветских стран. В действительности же, ЕАЭС должен формироваться, по своей сути, как неотъемлемая составная часть Большой Европы.

Финансово-экономические кризис в Евросоюзе существенным образом затрагивает интересы России и других постсоветских стран, поскольку ЕС является крупнейшим их внешнеэкономическим и торговым партнером. Более того, от состояния дел в Евросоюзе в значительной мере зависят перспективы мировой экономики, в том числе интеграционных процессов в ЕАЭС. Именно поэтому Россия и другие постсоветские страны заинтересованы в сильном ЕС, в реализации потенциала их партнерства, которое должно быть направлено на повышение конкурентоспособности евразийского континента.

Не меньшее значение имеют отношения России и других постсоветских стран с США и Китаем, от позиции которых во многом и даже в решающей степени зависят интеграционные планы по формированию ЕАЭС.

Является очевидно ошибочным со стороны США подход, согласно которому создание ЕАЭС противоречит действующей стратегии национальной безопасности США, которая направлена на недопущение возникновения на территории Евразии политического, экономического и военно-стратегического образования, способного ограничить контроль США над этим пространством. В большей или меньше степени, это может быть отнесено также и к стратегии Китая.

Действительно, создание ЕАЭС будет означать, фактически, демонтаж современного американского доминирования в мире и постепенный переход к формированию многополярной мировой структуры. В этом многополярном мире США могут остаться крупной экономической и политической державой, но только не мирового, а крупного регионального масштаба. Точно так же, как и Китай.

Но такой сценарий развития выгоден, на самом деле, США и всем другим субъектам международ- ных отношений - Евросоюзу, Китаю, России и ее партнерам. Поскольку в современных условиях мирового развития, связанных с серьезными глобальными угрозами, необходимо не сосредоточение в каком-либо центре всей экономической и геополитической ответственности и соответствующих затрат, а, напротив - их рассредоточение. Именно в этом и должна состоять глобально-региональная роль ЕАЭС.

Одна из основных проблем отношений России и США состоит в том, что политический диалог и сотрудничество не имеют под собой сильной экономической основы, объемы торговли и взаимных инвестиций не отвечают потенциалу их экономик. Поэтому эти отношения подвержены сильным конъюнктурным перепадам. Особенно востребовано тесное и доверительное взаимодействие России и США в периоды международной турбулентности и экономических кризисов. И это является одним из сдерживающих факторов создания ЕАЭС.

Отсюда следует очевидная необходимость качественного прорыва в экономических отношениях между России и США, но при одном фундаментальном условии - равноправности партнерства. Представляется, что создание ЕАЭС, изменение конфигурации на евразийском пространстве позволит сделать такой прорыв. И не только в отношениях с США, но и отношениях с Евросоюзом и Китаем.

Сбалансированная система партнерства ЕАЭС с США, Евросоюза и Китаем создаст условия для изменения сложившейся экономической и геополитической конфигурации евразийского континента. Это позволит ее участникам, в том числе постсоветским странам, занять достойное место в мире XXI века и совместно обеспечивать долгосрочную устойчивость глобального развития.

Таким образом, ЕАЭС призван стать одним из ключевых полюсов многополярного мира, используя традиционно сильные стороны Евразии для формирования сбалансированной системы партнерства - огромные территории, энергетику и природные ресурсы. Вопрос, также традиционно, состоит в доступе к высоким технологиям, определяя пока технологическую зависимость ЕАЭС от Евросоюза и США.

Очевидно, что часть такой зависимости и должна быть снята за счет модернизации и рационального использования сохранившегося промышленного, научно-технического и технологического потенциала ЕАЭС. Прежде всего, эти процессы должны быть инициированы Россией - ядром ЕАЭС. 
В современном мире одно из ключевых мест в мировых и региональных процессах принадлежит России, как одному из важнейших гарантов безопасности в мире и во многих регионах, прежде всего, в Евразии. Поэтому в интересы Запада (США и Евросоюза) и Востока (Китая) объективно не должно входить ослабление социально-экономических и геополитических позиций России.

Этот достаточно очевидный тезис подвергается сомнению многими геополитическими и экономическими конкурентами России, а также отдельными экспертами. Тем не менее, для такого подхода есть и серьезные основания, которые связаны, прежде всего, с определенным социально-экономическим и технологическим отставанием России. Это является сдерживающим фактором для постсоветской интеграции и возложения на Россию функций ядра такой интеграции, а также для перехода в зону ее влияния евразийского пространства.

Россия - это часть сложного мира и необратимого процесса глобализации, который распространяется на все большие пространства. Поэтому Россия должна четко определить свое место в мировых и региональных экономических и политических процессах, восстановить статус мировой державы, прежде всего, влияние в постсоветских странах. Как следствие этого - обеспечить переход от однополярного к многополярному миру, обеспеченному соответствующей системой коллективных прав и ответственности.

Становление России как ядра евразийской интеграции, а также локомотива экономической и политической модернизации в ЕАЭС - ключевое и единственное на евроазиатском континенте решение многих глобальных и региональных проблем, вызываемых глобализацией и угрожающих человечеству. Насколько эффективно и своевременно будет реализовано это решение зависит, главным образом, от политической воли России.

Поэтому достижение и сохранение долгосрочной устойчивости и эффективности развития России на евроазиатском континенте и должно составлять основу ее геополитической доктрины. Такая доктрина должна включать систему мер, направленных на упорядочение и оптимальную организацию географических, экономических и социальных пространств не только России и других постсоветских стран, но и всего евразийского континента.

Доктрина должна быть направлена на достижение пространственной целостности евразийско- го континента, как важнейшего условия адаптации составляющих его стран, к меняющимся пространственным и временным циклическим условиям развития. Эта целостность позволит преодолевать усиливающиеся как пространственный хаос, так и внешние угрозы для этих стран.

Данная задача должна решаться, прежде всего, посредством трансформации внешних пространств (пространства постсоветских стран) в единое внутреннее пространство ЕАЭС, а также установлением с внешними пространствами устойчивых геополитических и экономических союзов.

Это позволит осуществить переход России, совместно с другими постсоветскими странами в формате ЕАЭС, в состав мирового центра на правах сверхкрупной региональной евразийской державы. Более того, это позволит закрепить за ЕАЭС одно из ключевых мест в мировой системе, а также функции одного из генераторов экономической и политической глобализации, в равноправной конкуренции с другими странами и блоками.

Сближение с Западом и Востоком для реализации нового интеграционного проекта в Евразии и создания ЕАЭС может стать краеугольным камнем внутренней и внешней политики современной России. Оно является важнейшим условием сохранения и социально-экономического и политического развития не только России, но и других постсоветских стран.

Для реализации этой задачи и роли России в интеграционных процессах необходимо, прежде всего, выявить основные внутренние и внешние причины неблагоприятного пока места России в мировой системе, которые сдерживают ее развитие, вынуждают сохранять высокий уровень политической и социально-экономической закрытости в отношении внешнего мира, ведут к неполному участию России в ряде международных организаций. Более того, причины, которые выталкивают Россию в мировую периферию.

Совокупность подобных причин оказала в свое время решающее негативное, в том числе разрушительное влияние на социально-экономическое и политическое развитие Российской империи и СССР. Поэтому при реализации нового интеграционного проекта ЕАЭС необходимо четкое понимание прошлых ошибок и просчетов во избежание повторения ошибок предыдущих интеграционных проектов.

Представляется, что совокупность внутренних причин допущенных ранее просчетов связана с не- 


\section{Политика и общество $5(101) \cdot 2013$}

достаточно корректной и полной оценкой особенностей географического, а также социально-экономического и политического пространства России. С одной стороны, это относительно однородный и единый центр, включающий ряд ведущих крупных центральных городов и регионов (главным образом, в европейской части России). С другой стороны, это относительно неоднородная и многогранная периферия ${ }^{8}$, которая включает множество ведомых крупных, средних и малых (в том числе заброшенных, неосвоенных) городов и регионов (главным образом, в восточной части России $)^{9}$.

Такая структура пространств России является одной из причин односторонней, со стороны центра, экономической и социальной экспансии и дискриминации периферии, допущения значительного межрегионального экономического и социального неэквивалентного обмена. Более того, причиной неравномерного расселения населения и распределения трудовых, финансовых и сырьевых ресурсов, доходов и расходов и, поэтому, источником демографических проблем в России. Такая ситуация подавляет внутреннюю периферию, как города, так и целые регионы, еще более закрепляет их отсталость, тормозит модернизацию и интеграционные процессы.

В свою очередь, внешние причины еще невысокого места России в мировой системе связаны с наличием вокруг России, на западном, южном и восточном направлениях, более развитой и, как правило, агрессивной экономической, социальной и демографической среды. Агрессивность этой среды состоит в том, что она прямо либо косвенно осуществляет в отношении России целенаправленную внешнюю экономическую и политическую экспансию и дискриминацию, реализует внешний неэквивалентный обмен. Тем самым закрепляет за Россией статус сырьевой страны, фактически пассивного поставщика сырьевых ресурсов для Запада - США и Евросоюза, а также для развивающегося Востока - Китая.

Более того, возможная стратегическая цель такой экспансии - «расчистка» территории России для демографического сдвига на евразийском континен-

\footnotetext{
${ }^{8}$ Борисова М.М. Административно-территориальные единицы с особым статусом в объединенных субъектах Российской Федерации // Гуманитарные науки и образование. 2010. № 3 .

${ }^{9}$ Туровский Р.Ф. О состоянии и перспективах политической регионалистики // Политическая наука. 2011. № 4. С. 10 - 30.
}

те, размещения иностранных и транснациональных несырьевых (в том числе отсталых) секторов экономики. И, как следствие, для создания адаптированных к таким секторам культурных, социальных и политических систем и ценностей, большей частью отсталых. Такая ситуация подавляет Россию, закрепляет ее отсталость, тормозит модернизацию и интеграционные процессы.

Очевидно, что эти причины имеют объективный характер, в целом унаследованы Россией от Российской империи и СССР. Однако существуют также и субъективные факторы, которые связаны с отдельными не вполне корректными подходами к формированию и реализации внутренней и внешней политики России.

Так, вместе с множеством субъективных причин, связанных с преднамеренной или случайной ошибочностью внутренней ${ }^{10}$ и внешней политики, одна из главных из них - внециклический подход к экономике, а следовательно и к политике.

Именно такой подход усилил в период экономического кризиса 80-х - 90-х годов XX века действие негативных внутренних и внешних объективных условий в СССР, вызвал ослабление экономики и политики СССР и его распад со многими разрушительными глобальными и региональными последствиями ${ }^{11}$. Как и ранее, в период экономического кризиса начала XX века, такой же подход вызвал распад Российской империи с во многом аналогичными последствиями. Отголоски всех этих процессов продолжали иметь место в России в течение всех 90-х годов XX века, в результате которых Россия была вытеснена на мировую периферию.

Таким образом, основная задача внутренней и внешней политики России сегодня состоит в том, чтобы искоренить указанные внутренние и внешние причины социально-экономической и политической отсталости России. Путь к этому лежит через ликвидацию внутренней и внешней дискриминации, внутреннего и внешнего неэквивалентного обмена, в том числе посредством реализации нового интеграционного проекта ЕАЭС.

\footnotetext{
${ }^{10}$ Кондратович И.В. Региональная элита и проблемы ее формирования // Экономические науки. 2010. Т. 65. № 4. С. 166170.

${ }^{11}$ Соловьев А.И. Политическая регионалистика и исследования в регионах России // Политическая наука: Ежегодник РАПН 2010. М.: РОССПЭН. 2011. 494 c.
} 
Современная экономическая ситуация в России и других постсоветских странах характеризуется тремя ключевыми проблемами, практически аналогичными ранее для Российской империи и СССР. Это - сильная зависимость от экспорта природных ресурсов, низкая конкурентоспособность несырьевых секторов и слабость финансового (банковского) сектора экономики.

Все это сводится в целом к одному важнейшему вопросу, а именно чрезмерному доминированию в России и других постсоветских странах внешних факторов над внутренними. В итоге - к чрезмерной их внешней экономической, в том числе бюджетной и платежной зависимости от США, Евросоюза и не в последнюю очередь еще и Китая. При этом такое положение определяется, преимущественно, их чрезмерной зависимостью от внешних краткосрочных и спекулятивных капиталов и финансовых операций, от внешнего спроса на их сырьевые товары.

При этом действие внешних факторов как и внешний спрос ни Россией, ни другими постсоветскими странами практически не контролируются. Поэтому такая ситуация приобретает все более опасный характер для экономик России и ее ближайших партнеров.

Между тем, проблема внешней зависимости имеет негативные последствия не только в сфере экономики. Такая зависимость может перейти и уже отчасти переходит во внешнюю культурную, социальную, политическую и геополитическую зависимость России и других постсоветских стран. Очевидно, что это является угрозой для их государственности и вызывает естественное, с одной стороны, отторжение внешних факторов, а с другой, такое же естественное встречное интеграционное движение.

Очевидна поэтому необходимость определенной корректировки внутренней и внешней политики России и других постсоветских стран, смещение ее вектора от стремления лишь остановить ухудшение сложившейся ситуации, но и перейти к системному ее изменению. Дальнейшее ухудшение ситуации может привести к крупным и негативным геополитическим, демографическим и иным сдвигам на всем евроазиатском континенте.

Действительно, сохраняющаяся социально-экономическая и политическая отсталость постсоветских стран представляет собой одну из главных причин сильного давления на них со стороны наиболее развитой и ведущей части мировой системы, прежде всего, США и Евросоюза. По той же причине подобное давление, хотя и в других формах, оказывалось в свое время и с той же стороны на Российскую империю и СССР.

В настоящее время такое давление принимает различные формы экономической, социальной и культурной экспансии и преследует при этом следующие цели. Во-первых - это блокирование восстановления экономик России и других постсоветских стран и создания ЕАЭС как самостоятельного регионального или даже мирового экономического и геополитического субъекта, который находится под влиянием России. Во-вторых - подтягивание экономик постсоветских стран, в отдельных секторах вплоть до уровня экономик развитых государств, а затем их взаимная интеграция либо даже поглощение.

Безальтернативность интеграции на постсоветском пространстве и заинтересованность постсоветских государств в такой интеграции означает, что для большинства из них существуют два варианта интеграции.

При первом варианте постсоветские страны, в том числе и Россия, будут иметь возможность самостоятельного выстраивать и формат, и условия создания и развития ЕАЭС. При втором же варианте такой возможности у постсоветских стран практически не будет, формат и условия создания и развития ЕАЭС будут им навязаны извне и, возможно, даже без их участия. Это значит, что при первом варианте интеграция постсоветских стран в ЕАЭС и создание ими наднациональных органов управления являются единственной альтернативой перспективе установления внешнего управления Россией и другими постсоветскими странами.

Главное в том, что в обоих этих вариантах интеграции безальтернативным ядром евразийской интеграции будет являться именно Россия. Поэтому такое важное значение и приобретает борьба за Россию, за ее экономическую и политическую модернизацию, а также внутреннюю и внешнюю политику. Именно в такой борьбе формируются сегодня практически все современные политические и экономические процессы в самой России и вокруг нее.

Однако помимо нового проекта евразийской интеграции с ядром России объективно существует и третий сценарий развития ситуации на евразийском континенте. И этот сценарий связывается с распа- 


\section{Политика и общество 5 (101) • 2013}

дом России и созданием на ее территории множества мелких зависимых стран и территорий под прямым внешним управлением. Такой исход будет иметь для евразийского континента и постсоветских стран еще более катастрофические последствия, чем распад СССР.

Одними из проявлений реальности реализации такого сценария являются современные геополитические процессы, которые обосновываются планами расширения НАТО на Восток, а Китая - на Запад. Фактически, планами по встречному их движению через территорию России и других постсоветских стран, прежде всего, как указано выше, в целях «расчистки» их территорий.

Эти процессы направлены на реализацию двух целей. С одной стороны, на сужение социально-экономического и политического пространств и влияния России на евразийском континенте. С другой стороны, на расширение аналогичных пространств и влияния на этом континенте других стран и блоков, прежде НАТО у западных и юго-западных границ России, а Китая - у ее восточных и юго-восточных границ.

Вероятность реализации указанного выше, третьего сценария связана с тем, что генеральная тенденция развития мировой системы сегодня состоит, как отмечалось выше, в сохранении сложившегося и пока еще существующего однополярного мирового порядка. Причем, сохранение такого порядка в интересах практически монопольного его носителя - США, возможно, совместно с Евросоюзом и Китаем, с вытекающими из этого позитивными и негативными последствиями для тех или иных стран.

Проблема в том, что для России и других постсоветских стран последствия такого развития событий будут, видимо, в большей мере негативными, чем позитивными. И это приведет к неизбежной и вынужденной, в том числе навязанной извне, главным образом, со стороны США и НАТО, экономической и геополитической изоляция или самоизоляция России и других постсоветских стран как реакции на эти последствия. Безусловно, одной из форм такой самоизоляции, в случае реализации именно этой концепции развития, может стать ЕАЭС.

Вероятность навязывания России и другим постсоветским странам изоляции будет повышаться с ухудшением их экономического и политического состояния. Причем возможность такой изоляции значительно увеличится в период очередного мирового экономического кризиса.

\section{Библиография:}

1. Соловьев А.И. Политическая регионалистика и исследования в регионах России // Политическая наука: Ежегодник РАПН 2010. М.: РОССПЭН. 2011. 494 с.

2. Туровский Р.Ф. О состоянии и перспективах политической регионалистики // Политическая наука. 2011. № 4. С. $10-30$.

3. Бусыгина И.М. Модернизация и проблема эффективности государства // Политическая модернизация России в экспертном сознании. М.: Изд-во "Проспект", 2011. С. 86-97.

4. Современная политическая теория / Авт.-сост. Д. Хэлд. М., 2001.

5. Гаджиев К.С. Геополитика. М.: Международные отношения, 1997.

6. Тишков В. А. Этнология и политика. Научная публицистика. М., 2001.

7. Борисова М.М. Административно-территориальные единицы с особым статусом в объединенных субъектах Российской Федерации // Гуманитарные науки и образование. 2010. № 3 .

8. Кондратович И.В. Региональная элита и проблемы ее формирования // Экономические науки. 2010. Т. 65. № 4. С. 166-170.

9. Барсуков А.М. Политический кризис бельгийского федерализма // Вопросы политологии. 2012. №1.

\section{References (transliteration):}

1. Solov'ev A.I. Politicheskaya regionalistika i issledovaniya $\mathrm{v}$ regionakh Rossii // Politicheskaya nauka: Ezhegodnik RAPN 2010. M.: ROSSPEN. 2011. $494 \mathrm{c}$.

2. Turovskiy R.F. O sostoyanii i perspektivakh politicheskoy regionalistiki // Politicheskaya nauka. 2011. № 4. C. $10-30$.

3. Busygina I.M. Modernizatsiya i problema effektivnosti gosudarstva // Politicheskaya modernizatsiya Rossii v ekspertnom soznanii. M.: Izd-vo «Prospekt», 2011. S. 86-97.

4. Sovremennaya politicheskaya teoriya / Avt.-sost. D. Kheld. M., 2001.

5. Gadzhiev K.S. Geopolitika. M.: Mezhdunarodnye otnosheniya, 1997. 
Международная политика

6. Tishkov V. A. Etnologiya i politika. Nauchnaya publitsistika. M., 2001.

7. Borisova M.M. Administrativno-territorial'nye edinitsy s osobym statusom v ob'edinennykh sub'ektakh Rossiyskoy Federatsii // Gumanitarnye nauki i obrazovanie. 2010. № 3.
8. Kondratovich I.V. Regional'naya elita i problemy ee formirovaniya // Ekonomicheskie nauki. 2010. T. 65. № 4. S. 166-170.

9. Barsukov A.M. Politicheskiy krizis bel'giyskogo federalizma // Voprosy politologii. 2012. №1. 